\title{
CAPACIDADE PREDITIVA DA DRE: A ESCOLHA NORMATIVA BRASILEIRA FAVORECE?
}

Lívia Maria Lopes Stanzani'

Sílvio Hiroshi Nakao²

\section{Resumo:}

Objetivo: Analisar se a obrigatoriedade de apresentação das despesas por função na face da DRE no Brasil afeta a capacidade preditiva dos usuários, especialmente dos analistas, mesmo com a apresentação também obrigatória das despesas por natureza nas notas explicativas.

Método: A amostra é composta por 54 empresas brasileiras de capital aberto, observadas durante cinco anos. As empresas foram segregadas em dois grupos, de acordo com o seu nível de alavancagem operacional. Por meio da técnica de análise de dados em painel, analisou-se a capacidade preditiva das diferentes classificações das despesas (função e natureza) em relação ao lucro futuro e às previsões dos analistas de mercado.

Resultados/Discussão: Os resultados mostram que a classificação das despesas por natureza é mais preditiva de lucro futuro quando comparada à classificação por função. No entanto, as evidências sugerem que os analistas utilizam a informação apresentada na DRE (por função) para realizarem projeções, mesmo com a disponibilidade das despesas por natureza em nota explicativa, o que pode afetar a sua assertividade. Ademais, é possível inferir que o erro nas projeções dos analistas tende a ser maior quando eles analisam empresas com maior alavancagem operacional.

Contribuições: $\mathrm{O}$ artigo contribui com a literatura de escolhas contábeis ao trazer evidências de que a restrição imposta por meio de normatização ao método de apresentação das despesas na DRE pode limitar a capacidade preditiva das informações contábeis a nível nacional, além de influenciar a qualidade das projeções dos analistas de mercado.

Palavras-chave: Qualidade da informação. Escolhas contábeis. Despesas por função. Despesas por natureza. Previsão de analistas.

Imlstanzani@usp.br. Universidade de São Paulo, São Paul-SP. Brasil. https://orcid.org/0000-0001-8776-879X

${ }^{2}$ shnakao@usp.br. Universidade de São Paulo, São Paulo

-SP. Brasil. https://orcid.org/0000-0003-3976-8407 


\title{
PREDICTABILITY OF INCOME STATEMENT: DOES THE BRAZILIAN REGULATORY CHOICE FAVOR?
}

\begin{abstract}
:
Objective: Analyze whether the mandatory presentation of expenses by function in the face of the Income Statement in Brazil affects the predictive capacity of users, especially analysts, even with the mandatory presentation of expenses by nature in the footnotes.

Method:The sample contains 54 publicly traded Brazilian companies that were observed over a period of five years. The companies were segregated into two groups, according to their level of operational leverage. We use a panel data analysis technique to analyze the predictive capacity of the different classifications of expenses (function and nature) in relation to future earnings and analysts' forecasts. Results/Discussion: Based on the results, we verified that the classification of expenses by nature is more predictive of future earnings when compared to the classification by function. However, the evidences suggest that analysts use the information presented in the Income Statement (by function) to make projections, even with the availability of expenses by nature in the footnotes, which can affect their assertiveness. Furthermore, it is possible to infer that the error in the analysts' forecasts tends to be greater when they analyze companies with a high level of operational leverage.

Contributions: This study contributes to the literature by bringing evidence that the restriction imposed by standardizing the method of presenting expenses in the Income Statement can limit the predictive capacity of accounting information at the national level and influence the quality of analysts' forecasts.
\end{abstract}

Keywords: Quality of information. Accounting choices. Expenses by function. Expenses by nature. Analysts' forecast. 


\section{INTRODUÇÃO}

[ ste trabalho busca analisar se a obrigatoriedade de apresentação das despesas por função na face

da DRE no Brasil afeta a capacidade preditiva dos usuários, especialmente dos analistas de mercado, mesmo com a apresentação também obrigatória das despesas por natureza nas notas explicativas.

De acordo com o pronunciamento contábil CPC 26 (IAS 1), são permitidas duas formas de apresentação das despesas na Demonstração do Resultado do Exercício (DRE), função ou natureza, o que é caracterizado como uma escolha contábil de apresentação para as companhias. No entanto, o IASB ressalta que a classificação com base na natureza possui capacidade preditiva para o usuário e, portanto, a empresa que optar pela divulgação por função deve apresentar, também, uma nota explicativa com a discriminação das despesas por natureza (CPC 26, 2011).

No Brasil, o artigo 187 da Lei 6.404/76 determina que as empresas discriminem suas despesas na DRE de forma semelhante à segregação por função, o que resulta em uma escolha predefinida para todas as empresas brasileiras, não sendo permitido, assim, que estas façam a apresentação da DRE com as despesas segregadas por natureza em sua face, mas apenas em notas explicativas.

Estudos desenvolvidos por Anagnostopoulou (2010), Bradshaw, Miller e Serafeim (2009) e Lim, Lim e Lobo (2013) sugerem que as escolhas contábeis realizadas no âmbito do reconhecimento e da mensuração das informações podem interferir na capacidade preditiva e na acurácia das projeções dos analistas de mercado. Nesse mesmo contexto, Fairfield, Sweeney e Yohn (1996) e Barth, Cram e Nelson (2001) defendem que a escolha do formato de apresentação das informações nas demonstrações financeiras também pode influenciar os usuários na realização de suas projeções.

Como a norma IFRS/CPC permite a escolha contábil sobre a apresentação das despesas na DRE, entende-se que essa escolha deve ser feita pelo gestor da entidade, de maneira a permitir uma informação relevante e que represente mais adequadamente sua realidade econômica. Ao retirar a possibilidade de se fazer essa escolha contábil, a lei brasileira pode acabar reduzindo a capacidade preditiva da informação contábil.

Entretanto, o efeito da restrição de escolha contábil ainda não está suficientemente descrito na literatura. A literatura sobre escolha contábil é relativamente grande, envolvendo os seus diversos efeitos sobre a qualidade da informação contábil e sobre as decisões dos usuários, mas a imposição de uma restrição em nível país para uma escolha prevista na norma internacional ainda demanda estudo.

Nesse cenário, surge o problema de pesquisa do estudo: como a restrição da escolha contábil imposta em nível país para a apresentação da demonstração de resultados pode afetar a capacidade de os usuários predizerem fluxos de caixa futuros?

Dado que não é possível obter informação divulgada sobre qual teria sido a escolha contábil de cada gestor caso não houvesse a restrição imposta, o objetivo do trabalho é analisar a influência da classificação das despesas por função na capacidade preditiva da DRE publicada pelas empresas brasileiras, considerando que as despesas por natureza também são divulgadas nas demonstrações financeiras em nosso país.

Para tanto, foi analisada uma amostra de empresas brasileiras, não-financeiras, de capital aberto, durante um período de cinco anos, utilizando-se como metodologia a abordagem de análise de dados em painel. Primeiramente, foi testado se a apresentação das despesas por natureza possui maior ou menor capacidade preditiva do que a apresentação por função. Este teste não é capaz de atingir o objetivo do 
trabalho por si só, mas avalia o pressuposto de que a apresentação das despesas por natureza poderia trazer maior capacidade preditiva para os usuários. Para avaliar se a apresentação obrigatória de despesas por função na DRE reduz a sua capacidade preditiva, partiu-se do pressuposto de que os usuários preferem utilizar a DRE a nota explicativa. Nesse sentido, foi possível verificar se a apresentação por função afeta negativamente a acurácia das projeções de analistas de mercado e em que situação isso ocorre.

Assim, este trabalho procura contribuir com a literatura de escolhas contábeis ao observar o caso do Brasil, que impôs por lei, em nível país, a impossibilidade de se fazer a escolha contábil de apresentação das despesas prevista na norma internacional. $\mathrm{O}$ artigo traz evidências empíricas de que a restrição imposta por meio de normatização pode limitar a capacidade preditiva das informações contábeis, afetando, assim, a qualidade da informação divulgada aos usuários. Ademais, as evidências sugerem que os analistas utilizam a informação apresentada na DRE (por função) para realizarem projeções, mesmo com a disponibilidade das despesas por natureza em nota explicativa, o que pode afetar a sua assertividade, especialmente para empresas com alto nível de alavancagem operacional.

\section{REVISÃO DA LITERATURA E DESENVOLVIMENTO DAS HIPÓTE-} SES

\subsection{Apresentação das informações contábeis: revisão da literatura}

Logo no início do século, Barth et al. (2001) incitaram discussões trazendo evidências de que a desagregação do lucro em fluxo de caixa e accruals aumenta significativamente o seu poder preditivo. Desde então, os estudos na área de qualidade da informação contábil defendem que a inclusão de itens não recorrentes na composição do lucro e as diferenças entre os métodos de mensuração trazidos pelos FASB e IASB podem ter aumentado a volatilidade do lucro (valor justo), reduzindo, assim, a sua persistência e o seu poder de predizer lucros futuros (Doukakis, 2010; Cutillas-gomariz, Sánchez-Ballesta, \& Yagüe, 2016). Por outro lado, também existem evidências de que a utilização de informações mais próximas à realidade econômica pode tornar o lucro das empresas mais estável ao longo do tempo, aumentando, assim, a sua capacidade preditiva (Cutillas-gomariz et al., 2016).

Apesar da falta de consenso sobre os benefícios trazidos pelas IFRS, existem evidências empíricas de que a forma de mensuração e reconhecimento dos itens nas demonstrações contábeis pode afetar a capacidade preditiva da informação (Jones \& Smith, 2011; Bratten, Causholli, \& Khan, 2016). Nesse contexto, a literatura mostra que as informações que compõem o lucro apresentam conteúdo adicional e diferenças em suas capacidades preditivas que devem ser levadas em consideração (Lipe, 1986; Fairfield et al., 1996; Dechow \& Ge, 2006; Doukakis, 2010).

De acordo com Fairfield et al. (1996) e Barth et al. (2001), isto se torna mais evidente à medida que a segregação do lucro em componentes do fluxo de caixa e accruals aumenta a sua capacidade preditiva, o que é explicado pelo fato de os usuários não conseguirem diferenciar muito bem estas informações quando as mesmas se encontram agregadas na composição do lucro (Sloan, 1996). Pode-se dizer, então, que o usuário utiliza a informação disponível para realizar predições, porém, nem sempre a forma como ela é apresentada nas demonstrações financeiras é a que maximizaria a utilidade e a acurácia de suas projeções.

Nessa mesma linha, o trabalho de Charitou, Karamanou e Kopita (2018) propõe a análise dos incentivos para a escolha de apresentação das despesas financeiras na Demonstração do Fluxo de Caixa (DFC). Os autores apontam evidências de que a escolha contábil que envolve a forma de classificação 
desta informação na DFC pode afetar a avaliação da empresa pelos credores e investidores, sendo este, portanto, um incentivo que pode direcionar a escolha contábil das entidades.

Koonce, Leitter e White (2019) também sustentam teoricamente que a apresentação das informações contábeis pode interferir na qualidade da informação que é divulgada aos stakeholders. $O$ estudo confrontou três formatos diferentes para a apresentação de itens que compõem o balanço patrimonial e constataram que a apresentação vinculada de ativos e passivos (raramente adotada na prática), quando estes são, naturalmente, interligados, permite que os usuários das demonstrações financeiras consigam comparar melhor empresas em diferentes economias, o que melhoraria as suas decisões. De acordo com os autores, em uma análise envolvendo ativos e passivos derivados de operações de hedge, por exemplo, os usuários podem interpretar de forma equivocada os riscos atrelados aos fluxos de caixa futuros da empresa ao analisar um balanço patrimonial que não apresenta os ativos e passivos de forma vinculada, mesmo que essa informação esteja detalhada em nota explicativa (Koonce et al., 2019).

Guo e Zhou (2018) realizaram um experimento com estudantes a fim de identificar se a desagregação das despesas operacionais por natureza ajudaria na realização de julgamentos em cenários de recessão e expansão econômica. Os resultados mostraram que a desagregação das informações auxiliou os participantes a tomarem melhores decisões de investimentos. Por outro lado, enfatizou-se que as evidências obtidas ficaram restritas ao grupo de "investidores não profissionais e não sofisticados" que participaram do experimento, já que analistas de crédito, investidores profissionais e auditores estariam menos sujeitos aos efeitos decorrentes da desagregação das despesas na DRE em decorrência da sua maior familiaridade com as demonstrações financeiras, segundo os autores (Guo \& Zhou, 2018).

Em contrapartida aos estudos apresentados, Guragai, Attachot \& Peabody (2020) trazem evidências de que, no âmbito do US GAAP, a escolha de apresentação das informações sobre operações descontinuadas pelas empresas, agregando ou desagregando informações discricionariamente, não afetaria a avaliação dos investidores dessas empresas. Isso nos mostra que ainda não há um consenso na literatura sobre como a apresentação das informações nas demonstrações financeiras pode afetar a tomada de decisão dos diferentes usuários, nem sobre como alterações no formato de apresentação podem interferir na capacidade preditiva e na qualidade da informação reportada ao mercado.

\subsection{Apresentação das despesas e desenvolvimento das hipóteses}

As hipóteses desenvolvidas neste estudo estão sustentadas na proposição de que o maior detalhamento apresentado pelo método da natureza pode aumentar o valor preditivo da informação sobre despesas para o usuário. Ao contrário do método da função, a classificação por natureza auxilia na determinação da magnitude e do nível de variabilidade das despesas entre os períodos, o que, por sua vez, pode ser informação relevante para o usuário no processo de previsão do lucro futuro.

Desta forma, a escolha contábil que envolve a classificação das despesas na DRE, quando permitida legalmente, pode proporcionar informações com diferentes capacidades preditivas e que devem ser investigadas pela literatura. Mesmo que a classificação por natureza também esteja disponível em nota explicativa, sabe-se que a DRE apresenta uma informação mais sistematizável, sendo mais tradicionalmente utilizada para a tomada de decisão, o que significa que a informação sobre despesas divulgada em nota explicativa pode não ser utilizada sistematicamente pelos usuários. Segundo Frederickson, Hodge e Pratt (2006), os usuários são mais propensos a valorizar determinada informação se esta estiver reconhecida nas demonstrações financeiras ao invés de apenas divulgada em nota explicativa. 
Assim, como a informação sobre a variabilidade das despesas não é facilmente identificável na DRE por função, o erro nas projeções tende a ser maior à medida que os custos fixos embutidos são maiores. Para exemplificar a situação proposta, a Tabela 1 sintetiza a proposição das hipóteses de pesquisa. Trata-se de uma ilustração hipotética, na qual seria possível afirmar que as "despesas com materiais" se referem somente às despesas variáveis e a "despesas com mão-de-obra" se referem somente às despesas fixas.

Tabela 1- Relação entre custo fixo, despesas e valor preditivo.

\begin{tabular}{|c|c|c|c|c|c|c|c|}
\hline \multicolumn{4}{|c|}{ Baixo CF/CV } & \multicolumn{4}{|c|}{ Alto CF/CV } \\
\hline $\begin{array}{l}\text { Despesas por } \\
\text { natureza }\end{array}$ & $\mathrm{t}$ & $\begin{array}{c}t+1 \text { realizado } \\
(10 \%)\end{array}$ & $t+1 \underset{(10 \%)}{\text { projetado }}$ & $\begin{array}{l}\text { Despesas por } \\
\text { natureza }\end{array}$ & $\mathrm{t}$ & $\begin{array}{c}\mathrm{t}+1 \text { realizado } \\
(10 \%)\end{array}$ & $\begin{array}{c}t+1 \text { projetado } \\
(10 \%)\end{array}$ \\
\hline Receita & 1000 & 1100 & 1100 & Receita & 1000 & 1100 & 1100 \\
\hline Materiais & 600 & 660 & 660 & Materiais & 200 & 220 & 220 \\
\hline MO Fixa & 100 & 100 & 100 & MO Fixa & 500 & 500 & 500 \\
\hline Lucro & 300 & 340 & 340 & Lucro & 300 & 380 & 380 \\
\hline Erro & \multicolumn{3}{|c|}{$0 \%$} & Erro & \multicolumn{3}{|c|}{$0 \%$} \\
\hline Despesas por função & $\mathrm{t}$ & $\begin{array}{c}\mathrm{t}+1 \text { realizado } \\
(10 \%)\end{array}$ & $\begin{array}{c}\mathrm{t}+1 \\
(10 \%)\end{array}$ & $\begin{array}{l}\text { Despesas por } \\
\text { função }\end{array}$ & $\mathrm{t}$ & $\begin{array}{c}\mathrm{t}+1 \text { realizado } \\
\quad(10 \%)\end{array}$ & $\begin{array}{c}t+1 \text { projetado } \\
(10 \%)\end{array}$ \\
\hline Receita & 1000 & 1100 & 1100 & Receita & 1000 & 1100 & 1100 \\
\hline CMV & 700 & 760 & 770 & CMV & 700 & 720 & 770 \\
\hline Lucro & 300 & 340 & 330 & Lucro & 300 & 380 & 330 \\
\hline Erro & \multicolumn{3}{|c|}{$3 \%$} & Erro & \multicolumn{3}{|c|}{$13 \%$} \\
\hline
\end{tabular}

Legenda: Erro: (Lucro t+1 projetado - Lucro t+1 realizado) / Lucro $t+1$ realizado.

A Tabela 1 ilustra a projeção de um aumento de 10\% no volume de vendas de duas empresas, com baixa e alta proporção de custos fixos, respectivamente, cujas despesas são apresentadas de duas formas diferentes: função e natureza. Nota-se que a projeção de lucro futuro pode ficar prejudicada quando utilizada a informação por função para a realização das previsões em qualquer uma das empresas, decorrente da projeção de $10 \%$ de aumento, que não existe, na parcela de custos fixos contida no valor do CMV.

Ademais, percebe-se que, em situações em que o CMV contém mais custos fixos embutidos, o erro na projeção ao se utilizar o método da função pode ser maior, afetando significativamente a acurácia das projeções realizadas. Isso acontece pois não é possível estimar com melhor precisão a variabilidade das despesas, diferentemente do que ocorre com empresas que apresentam menores custos fixos. No Brasil, apesar de ambas as classificações das despesas, função e natureza, estarem disponíveis nos demonstrativos financeiros das empresas, não se sabe qual delas os analistas realmente utilizam em seus modelos de previsão.

De acordo com a literatura, a acurácia das previsões dos analistas torna-se uma consequência da maior capacidade preditiva das informações divulgadas (Dechow, Ge, \& Schrand, 2010; Choi, Peasnell, \& Toniato, 2013), resultando em projeções mais relevantes e úteis para o mercado. Nesse sentido, diversos fatores podem influenciar a acurácia das previsões dos analistas, dentre eles, a análise detalhada não somente do lucro, mas de seus componentes, o disclosure apresentado pelas empresas, a qualidade da auditoria e as diferentes formas de mensuração (Basu, Hwang, \& Jan, 1998; Healy \& Palepu, 2001; Hope, 2003; Doukakis, 2010; Bradshaw et al., 2009; Dalmácio, Lopes, Rezende, \& Sarlo Neto, 2013).

Isto, por sua vez, sugere que os resultados obtidos com projeções de lucro para empresas brasileiras possam ser menos acurados do que poderiam ser, caso o analista utilize a informação por função, disponível na DRE, para a realização de suas projeções. Neste cenário, a primeira hipótese de pesquisa consiste em verificar a proposição de que os analistas, potencialmente, utilizariam a informação por função para realizar suas projeções, afetando, assim, a qualidade das suas previsões. 
H1: A acurácia das projeções dos analistas é afetada negativamente pela utilização do método de apresentação das despesas por função.

Assim, se a hipótese nula anterior for rejeitada, existirão evidências empíricas de que os analistas, potencialmente, utilizam a informação contida na DRE para realizar suas projeções. Isto indica que, além do método de apresentação das despesas na DRE conseguir afetar a acurácia de suas previsões, a magnitude do erro de previsão das projeções dos analistas também poderá ser maior à medida que for maior a proporção de despesas fixas presente na estrutura de custos das companhias.

Isto é explicado pela influência da persistência dos resultados na capacidade preditiva da informação. Segundo Francis, Lafond, Olsson e Schipper (2004), a persistência captura a recorrência do lucro no tempo, o que sugere uma redução da incerteza com relação aos resultados futuros. Assim, a análise da variabilidade das despesas dentro de uma empresa é relevante para as projeções dos analistas à medida que interfere diretamente na persistência dos resultados, ou seja, quanto maior a parcela de custos fixos, menor será a persistência (recorrência) do lucro ao longo do tempo (Tabela 1) e, consequentemente, menor o poder preditivo da informação para o usuário.

Assim, a segunda hipótese consiste em verificar a relação entre a proporção de custos fixos nas empresas e o erro nas projeções dos analistas. Se os analistas utilizarem a informação por função em suas projeções, quanto maior for a proporção de custos fixos na empresa, maior será erro observado em suas previsões.

H2: O erro das projeções dos analistas é maior quanto maior for a proporção de custos fixos.

\section{DESENHO DE PESQUISA}

Nesta seção serão detalhados os modelos econométricos, as variáveis e as técnicas de análise de dados utilizadas neste trabalho. Ressalta-se que as variáveis relacionadas às despesas por natureza foram coletadas, manualmente, por meio das notas explicativas e as demais variáveis foram obtidas por meio do banco de dados da plataforma Thomson Reuters.

\subsection{Dados e amostra}

A composição da amostra se deu de forma aleatória, com o intuito de permitir a inferência dos resultados obtidos para as demais empresas que compõem a Bolsa de Valores Brasileira. Assim, foram selecionadas, aleatoriamente, por meio de função aleatória do Microsoft Excel, 126 empresas brasileiras de capital aberto pertencentes a "Brasil, Bolsa e Balcão" (B3) (93\% de confiança). Foram excluídas as empresas que pertenciam ao setor financeiro, com muitas observações ausentes e que não possuíam dados de projeções de analistas por mais de três anos, resultando em uma amostra final de 54 empresas ( $90 \%$ de confiança), pertencentes a 9 setores. A proposição de segregação dos setores foi obtida do website infomoney. Posteriormente, os setores "mineração" e "petróleo e gás" foram agrupados no setor "exploração" e os setores "saúde", "transporte e logística" e "telecomunicações" formaram o setor de "serviços". Esse agrupamento foi baseado na similaridade entre esses setores e está apresentado em detalhes na Tabela 2.

As companhias foram observadas durante o período de 2010 a 2015, resultando em 246 observações ao longo do tempo e na aplicação de um painel desbalanceado. Quanto ao período de análise dos dados, este foi escolhido em função da obrigatoriedade de adoção das IFRS ter sido implementada no Brasil em 2010. A amostra foi segregada em dois grupos: empresas com alto nível de custos fixos ("alto CF") 
e baixo nível de custos fixos ("baixo CF"). Para retirar o efeito do tamanho das companhias analisadas, o indicador utilizado para segregar os grupos foi calculado com base na proporção de custos fixos em relação aos custos variáveis presentes em cada empresa, formando, assim, um índice percentual "custo fixo/custo variável".

Por fim, calculou-se o indicador do nível de custo fixo (CF/CV) para cada empresa da amostra e, em seguida, foi identificada a mediana destes valores. Calculou-se, também, a mediana do indicador para as empresas de cada setor e comparou-se os valores encontrados com a mediana amostral, que serviu como parâmetro para a segregação dos grupos. Desta forma, os setores que apresentavam mediana menor do que a mediana da amostra foram classificados como "baixo CF", enquanto os setores que apresentavam mediana maior do que a mediana da amostra foram alocados ao grupo "alto CF". A Tabela 2 evidencia as empresas que compõem a amostra e a classificação dos setores nos dois grupos.

Tabela 2-Empresas da amostra segregadas por grupos.

\begin{tabular}{|c|c|c|c|c|}
\hline ID & CLASSIFICAÇÃO & No EMPRESAS & MEDIANA & GRUPO \\
\hline 1 & Consumo e Varejo & 14 & $44 \%$ & \multirow{2}{*}{ BAIXO CF } \\
\hline 5 & Industrial & 10 & $34 \%$ & \\
\hline 7 & Serviços (saúde, transporte, logística e telecomunicações) & 10 & $41 \%$ & \multirow{2}{*}{ ALTO CF } \\
\hline 2 & Energia e Saneamento & 10 & $49 \%$ & \\
\hline 4 & Construção e Imobiliário & 7 & $54 \%$ & \\
\hline 6 & Exploração (mineração, petróleo e gás) & 3 & $50 \%$ & \\
\hline Total amostra & & 54 & & $44 \%$ \\
\hline
\end{tabular}

Legenda: Erro: (Lucro $t+1$ projetado - Lucro $t+1$ realizado) / Lucro $t+1$ realizado.

Vale ressaltar que as informações sobre custos fixos e variáveis não são disponibilizadas ao usuário externo e, portanto, como proxy para custos fixos foram utilizadas as informações sobre "depreciação" e "pessoal", já que estas contas não oscilam proporcionalmente em função do nível de vendas, e para custos variáveis foi utilizada a informação sobre "materiais e serviços", já que, provavelmente, estes gastos oscilam de acordo com a quantidade de produtos (mercadorias) vendidos ou serviços prestados de um período para outro.

\subsection{Modelos estatísticos e variáveis}

Os modelos estatísticos desenhados foram baseados nos estudos de Jones e Smith (2011) e Cutillas-Gomariz et al. (2016):

$$
\text { Lucro Líquido }_{\mathrm{t}+1}=\alpha+\beta \text { Despesas } \mathrm{t}+\mathrm{\varepsilon t} \text { (1) }
$$

O objetivo é verificar quanto do lucro em $\mathrm{t}+1$ pode ser explicado pelas informações sobre despesas (função e natureza) disponíveis em t e, assim, analisar a capacidade preditiva da informação por meio do $\mathrm{R}^{2}$ ajustado do modelo e do critério de Akaike. A Figura 1 apresenta todos os modelos teóricos utilizados no trabalho. 
Figura 1-Modelos teóricos

\begin{tabular}{|c|c|}
\hline & MODELOS \\
\hline Modelo 1 & $\mathrm{LL}_{\mathrm{t}+1}=\alpha+\beta 1 \mathrm{CMV}+\beta 2$ D. Vendas $+\beta 3$ D. Administrativas $+\varepsilon \mathrm{t}$ \\
\hline Modelo 2 & $\mathrm{LL}_{\mathrm{t}+1}=\alpha+\beta 1$ Materiais e Serviços $+\beta 2$ Depreciação $+\beta 3$ Pessoal $+\beta 4$ Outras $+\varepsilon \mathrm{t}$ \\
\hline Modelo 3 & Previsão analista ${ }_{\mathrm{t}+1}=\alpha+\beta 1 \mathrm{CMV}+\beta 2$ D. Vendas $+\beta 3$ D. Administrativas $+\varepsilon \mathrm{t}$ \\
\hline Modelo 4 & Previsão analista ${ }_{\mathrm{t}+1}=\alpha+\beta 1$ Materiais e Serviços $+\beta 2$ Depreciação $+\beta 3$ Pessoal $+\beta 4$ Outras $+\varepsilon \mathrm{t}$ \\
\hline Modelo 5 & Erro analista $_{\mathrm{t}+1}=\alpha+\beta 1 \mathrm{CMV}+\beta 2$ D. Vendas $+\beta 3$ D. Administrativas $+\varepsilon \mathrm{t}$ \\
\hline Modelo 6 & Erro analista ${ }_{\mathrm{t}+1}=\alpha+\beta 1$ Materiais e Serviços $+\beta 2$ Depreciação $+\beta 3$ Pessoal $+\beta 4$ Outras $+\varepsilon t$ \\
\hline
\end{tabular}

Legenda: $L L_{t+1}$ : corresponde ao lucro líquido em $t+1$; D. Vendas $t$ : corresponde ao total de despesas com vendas em $t$; $D$. Administrativas t: corresponde ao total de despesas administrativas em t; CMV : corresponde ao total de custo das mercadorias vendidas ou custo dos serviços prestados ou custo dos produtos vendidos em t.; Materiais e serviços t: corresponde ao custo com materiais e serviços em .; Depreciação : corresponde ao custo com depreciação, amortização e exaustão em t.; Pessoal t: corresponde ao custo com mão-de-obra e encargos associados em t.; Outras t: corresponde a parcela de custos que não conseguiu ser alocada aos demais itens em $t$. Previsão analista ${ }_{t+1}$ : corresponde à média das previsões dos analistas para $t+1$; Erro analista $_{t+1}$ : corresponde à diferença entre a média das previsões dos analistas para $t+1$ e o lucro realizado em $t+1$; $\varepsilon$ : corresponde ao erro do modelo.

Os dados foram obtidos das demonstrações contábeis consolidadas, quando este relatório estava disponível para a empresa, e se encontram padronizados. Para coletar as informações sobre as despesas por natureza, foram necessários alguns agrupamentos quando as empresas apresentavam um alto nível de abertura das informações em nota explicativa. No entanto, buscou-se manter um critério único de alocação para minimizar o subjetivismo envolvido. A variável "outras despesas" representa, na maioria das vezes, o valor apresentado pela própria empresa que foi divulgado em nota explicativa. Entretanto, em alguns casos, também possui em sua composição uma parcela de custo que, embora fosse detalhada, não podia ser alocada às demais variáveis devido à incerteza quanto a sua real natureza, como: tributos ou provisões de origem não especificadas ou muito abrangentes.

Vale ressaltar que algumas companhias optaram por divulgar apenas a natureza referente das despesas administrativas e com vendas, e não detalharam a composição do CMV. Assim, para garantir que, nestes casos, a alocação de valores altos à conta de "outras despesas" não pudesse prejudicar os resultados, foi realizado um teste de robustez, excluindo-se estas companhias da amostra (8 empresas).

\subsection{Tratamento dos dados}

Foi utilizada a técnica de análise de dados em painel, pois se pretendeu analisar o comportamento de várias empresas em uma série temporal. Os resultados dos testes de Chow, Breusch-Pagan e Hausman apontaram para a utilização do método de painel com efeitos fixos, com exceção do modelo que analisa o"erro do analista" como variável dependente (modelos 5 e 6) para o grupo "baixo CF", que apontou para a utilização de efeitos aleatórios.

Foram testados, também, os pressupostos necessários para a utilização do modelo linear (normalidade dos resíduos, homocedasticidade, multicolinearidade e autocorrelação). O teste de Shapiro-Wilk indicou ausência de normalidade dos resíduos e das variáveis. Detectou-se o problema de heterocedasticidade que, no entanto, foi corrigido por meio da utilização de dados robustos.

Verificou-se também a existência de autocorrelação entre as variáveis independentes, sugerindo que existe problema de multicolinearidade no modelo (Teste VIF). Entretanto, segundo Gujarati e Porter (2011), o único efeito da multicolinearidade é dificultar a obtenção de estimativas dos coeficientes com 
erros padrão pequenos, o que leva a erros maiores nos estimadores, fazendo com que eles não sejam parâmetros confiáveis para serem analisados. Sendo assim, se o principal objetivo da análise do modelo for a previsão, o problema de multicolinearidade não é significativo, já que o principal parâmetro analisado será o $R^{2}$ da regressão que, por sua vez, não é afetado (Gujarati \& Porter, 2011).

Por fim, para dar mais robustez ao trabalho, foram realizados três testes adicionais: o teste de Chow, para confirmar a presença de quebra estrutural entre os grupos "baixo $C F$ " e "alto $C F$ ", a repetição dos testes após a remoção das empresas que tinham o valor de CMV alocado à conta "outras despesas" $\mathrm{e}$ a corroboração dos resultados obtidos no modelo 1 e 2, substituindo-se a variável "lucro líquido" pelo "fluxo de caixa operacional".

\section{ANÁLISE E DISCUSSÃO DOS RESULTADOS}

Nesta seção serão apresentados os resultados obtidos, assim como as implicações teóricas e práticas deste estudo. As evidências empíricas encontradas serão confrontadas com os achados dos demais autores, evidenciados previamente na seção de referencial teórico, a fim de permitir uma melhor visualização das contribuições deste artigo para a literatura de escolhas contábeis e qualidade da informação contábil.

\subsection{Análise dos resultados}

Os resultados foram analisados e interpretados com base no poder explicativo dos modelos de apresentação das despesas, já que este é o objetivo do trabalho. Vale ressaltar que os coeficientes das variáveis independentes não puderam ser analisados em função do problema de multicolinearidade. Entretanto, um teste de robustez foi realizado, posteriormente, por meio do qual se conseguiu verificar a significância e analisar os coeficientes de cada variável.

Em um primeiro momento, testou-se o pressuposto da superioridade da capacidade preditiva da informação por natureza em relação à informação por função. Os resultados encontram-se apresentados na Tabela 3 e mostram que o poder explicativo $\left(R^{2}\right)$ do modelo 2 é significativamente maior que o do modelo 1, tanto para a amostra como um todo, quanto para os grupos separadamente. No grupo "baixo CF", embora o poder explicativo do modelo seja menor do que o apresentado pelo grupo "alto CF", a despesa por natureza continua sendo mais explicativa.

Esse resultado valida o pressuposto de que o método de apresentação por natureza é mais preditivo do que o método da função, independentemente do nível de custos fixos existente nas empresas. Assim, a validação desse pressuposto permite que seja dada continuidade ao estudo, pois confirma a proposição teórica trazida pelo IAS 1 (CPC 26), de que a informação por natureza possui maior capacidade preditiva, o que era tratado como premissa para o desenvolvimento das hipóteses de pesquisa.

Tabela 3- Teste do pressuposto da capacidade preditiva das despesas por natureza e por função.

\begin{tabular}{|c|c|c|c|c|}
\hline \multicolumn{5}{|c|}{ Modelo $1-L L t+1=a+b 1 C M V t+b 2 D$. Vendas $t+b 3 D$. Administrativas $t+\varepsilon t$} \\
\hline \multicolumn{5}{|c|}{ Amostra total } \\
\hline $\mathrm{R}^{2}$ Within & 0,500446 & & & \\
\hline Teste F & 11,7404 & & & \\
\hline P-valor (F) & $5,22 \mathrm{E}-06$ & & & \\
\hline Observaçōes & 246 & & & \\
\hline Akaike & 8273,999 & & & \\
\hline Variável & Coeficiente & Erro padrão & razão-t & p-valor \\
\hline constante & 3,49E+06 & $1,29 \mathrm{E}+06$ & 2,704 & $0,0092 * * *$ \\
\hline D. Vendas & $-0,175684$ & 1,38418 & $-0,1269$ & 0,8995 \\
\hline D. Adm & 988752 & 405526 & 2438 & $0.0181 * *$ \\
\hline
\end{tabular}




\begin{tabular}{|c|c|c|c|c|}
\hline CMV & $-0,804448$ & 0,216271 & $-3,720$ & $0,0005 * * *$ \\
\hline \multicolumn{5}{|c|}{ Baixo CF } \\
\hline $\mathrm{R}^{2}$ Within & 0,287304 & & & \\
\hline Teste F & 15,0499 & & & \\
\hline P-valor (F) & $2,69 \mathrm{E}-08$ & & & \\
\hline Observações & 149 & & & \\
\hline Akaike & 4315,41 & & & \\
\hline Variável & Coeficiente & Erro padrão & razão-t & p-valor \\
\hline constante & 77040,3 & 96523,4 & 0,7982 & 0,4265 \\
\hline D. Vendas & 0,0207778 & 0,103465 & 0,2008 & 0,8412 \\
\hline D. Adm. & 0,375809 & 0,513773 & 0,7315 & 0,466 \\
\hline CMV & 0,0806696 & 0,016645 & 4,8465 & 0,001 *** \\
\hline \multicolumn{5}{|c|}{ Alto CF } \\
\hline $\mathrm{R}^{2}$ Within & 0,605087 & & & \\
\hline Teste F & 128739 & & & \\
\hline P-valor (F) & $4,28 \mathrm{E}-41$ & & & \\
\hline № observações & 97 & & & \\
\hline Akaike & 3330,658 & & & \\
\hline Variável & Coeficiente & Erro padrão & razão-t & p-valor \\
\hline constante & $4,74 \mathrm{E}+06$ & $1,97 \mathrm{E}+06$ & 2,411 & $0,0262 * *$ \\
\hline D. Vendas & $-0,443896$ & 4,07784 & $-0,1089$ & 0,9145 \\
\hline D. Adm. & 12,4347 & 4,85678 & 2,56 & 0,0191 ** \\
\hline CMV & $-0,959242$ & 0,393472 & $-2,438$ & 0,0248 ** \\
\hline \multicolumn{5}{|c|}{ Modelo 2- $\mathrm{LL} t+1=\mathrm{a}+\mathrm{b} 1$ Materiais e Serviços $\mathrm{t}+\mathrm{b} 2$ Depreciação $\mathrm{t}+\mathrm{b} 3$ Pessoal $\mathrm{t}+\mathrm{b} 4$ Outras $\mathrm{t}+\mathrm{\varepsilon t}$} \\
\hline \multicolumn{5}{|c|}{ Amostra total } \\
\hline $\mathrm{R}^{2}$ Within & 0,674515 & & & \\
\hline Teste F & 1059,07 & & & \\
\hline P-valor (F) & $7,40 \mathrm{E}-50$ & & & \\
\hline Observações & 246 & & & \\
\hline Akaike & 8170,613 & & & \\
\hline Variável & Coeficiente & Erro padrão & razão-t & p-valor \\
\hline constante & $3,40 E+06$ & 776209 & 4,378 & $5,68 \mathrm{e}-05^{* * *}$ \\
\hline Depreciação & $-5,36079$ & 2,42786 & $-2,208$ & $0,0316 * *$ \\
\hline Materiais & 0,362929 & 0,229489 & 1,581 & 0,1197 \\
\hline Pessoal & $-1,20236$ & 1,13047 & $-1,064$ & 0,2923 \\
\hline Outras & 0,665137 & 0,143642 & 4,631 & $2,40 \mathrm{e}-05^{* * *}$ \\
\hline \multicolumn{5}{|c|}{ Baixo CF } \\
\hline $\mathrm{R}^{2}$ Within & 0,340709 & & & \\
\hline Teste F & 14,3407 & & & \\
\hline P-valor (F) & $1,81 \mathrm{E}-09$ & & & \\
\hline Observações & 149 & & & \\
\hline Akaike & 4305,805 & & & \\
\hline Variável & Coeficiente & Erro padrão & razão-t & p-valor \\
\hline constante & 44901,3 & 96112,7 & 0,4672 & 0,6413 \\
\hline Depreciação & 0,219049 & 0,167972 & 1,3041 & 0,1949 \\
\hline Materiais & 0,0364482 & 0,0154893 & 2,3531 & 0,0204 ** \\
\hline Pessoal & 0,47594 & 0,146174 & 3,256 & $0,0015^{* * *}$ \\
\hline Outras & 0,0434809 & 0,0659969 & 0,6588 & 0,5114 \\
\hline \multicolumn{5}{|c|}{ Alto CF } \\
\hline $\mathrm{R}^{2}$ Within & 0,74686 & & & \\
\hline Teste F & 7335,42 & & & \\
\hline P-valor (F) & $5,31 \mathrm{E}-30$ & & & \\
\hline
\end{tabular}




\begin{tabular}{|c|c|c|c|c|}
\hline No observações & 97 & & & \\
\hline Akaike & 3289,52 & & & p-valor \\
\hline Variável & Coeficiente & Erro padrão & razão-t & $7,88 \mathrm{e}-06^{* * *}$ \\
\hline constante & $6,75 \mathrm{E}+06$ & $1,11 \mathrm{E}+06$ & 6,062 & 0,1863 \\
\hline Depreciação & $-12,5351$ & 9,14293 & $-1,371$ & 0,2056 \\
\hline Materiais & 1,24168 & 0,947401 & 1,311 & 0,9676 \\
\hline Pessoal & 0,107204 & 2,60427 & 0,04116 & $0,0025 * * *$ \\
\hline Outras & 1,01032 & 0,289717 & 3,487 & \\
\hline
\end{tabular}

O resultado inicial indica que o estudo pode contribuir com a literatura sobre qualidade da informação contábil trazendo evidências empíricas sobre a capacidade preditiva dos métodos de apresentação das despesas. No caso do Brasil, onde não há a liberdade de escolha do método de apresentação das despesas na DRE, é possível inferir que a impossibilidade de as empresas optarem pelo método da natureza pode reduzir a qualidade da informação que é disponibilizada aos usuários.

Até o momento, a literatura tem mostrado que diferentes métodos de mensuração e reconhecimento da informação contábil podem afetar a capacidade preditiva dos usuários (Jones \& Smith, 2011; Bratten, et al., 2016). Nesse sentido, a validação desse pressuposto contribui com essa literatura ao apresentar evidências de que a forma de apresentação das despesas na DRE pode ser um fator relevante para a capacidade preditiva da informação contábil, também.

No contexto brasileiro, os resultados podem servir de sustentação para suscitar discussões sobre as consequências das diretrizes da lei $6.404 / 76$ no que diz respeito à aplicabilidade dos métodos de apresentação das despesas no cenário brasileiro, especialmente em relação à qualidade da informação divulgada ao usuário. Uma vez que os resultados mostram que a informação por natureza é mais preditiva de lucro futuro, este método poderia ser mais útil do que o da função para os usuários, caso fosse apresentado na DRE pela maioria das empresas.

Deste modo, se a validação do pressuposto sugere que a despesa por natureza é mais preditiva de lucro futuro, os analistas de mercado, como importantes usuários da informação contábil, deveriam realizar suas projeções com base na abertura por natureza, já que esta informação também está disponível em nota explicativa para as empresas brasileiras. Entretanto, apesar de a informação por natureza ter se mostrado relevante para as projeções de desempenho futuro, é possível que o analista não utilize essa informação. Nota-se na Tabela 4 que o poder explicativo dos modelos 3 e 4 não apresenta diferença significativa para a amostra como um todo, já que o $\mathrm{R}^{2}$ é de, aproximadamente, $32 \%$ para ambos os modelos e a diferença no valor do critério de Akaike é muito pequena.

Sendo assim, são apresentados indícios de que, apesar de o método da natureza ter se mostrado mais preditivo de desempenho futuro (Tabela 3), os analistas, potencialmente, utilizam a informação apresentada na DRE (função) para realizar suas projeções. Isso porque, caso utilizassem a informação por natureza, o modelo 4 deveria ser mais explicativo, assim como ocorreu nos modelos 1 e 2 .

Outra análise interessante pode ser feita ao se comparar os resultados dos dois grupos, separadamente. Nota-se que, para o grupo "alto CF", o poder explicativo dos modelos 3 e 4 é menor comparado ao obtido para o grupo "baixo CF". Isto se mostra relevante à medida que os resultados foram exatamente opostos para os modelos 1 e 2, que analisavam o lucro líquido como variável dependente, ou seja, se a magnitude dos resultados entre os grupos fosse uma característica da amostra, então, ela deveria ser mantida nos outros modelos. Isso sugere que a previsão do analista é menos acurada para empresas com alto nível de custos fixos, sendo este mais um indício de que os analistas utilizam a informação por função em seus modelos de previsão. Estes resultados sustentam e validam a hipótese H1. 
Tabela 4- Resultados obtidos para a variável dependente previsão do analista em t+1 (H1).

\begin{tabular}{|c|c|c|c|c|}
\hline \multicolumn{5}{|c|}{ Modelo 3- Previsão analista $t+1=a+b 1 C M V t+b 2$ D. Vendas $t+b 3$ D. Administrativas $t+\varepsilon t$} \\
\hline \multicolumn{5}{|c|}{ Amostra total } \\
\hline $\mathrm{R}^{2}$ Within & 0,328679 & & & \\
\hline Teste F & 5,08649 & & & \\
\hline P-valor (F) & 0,00361468 & & & \\
\hline Observações & 246 & & & \\
\hline Akaike & 8059,112 & & & \\
\hline Variável & Coeficiente & Erro padrão & razão-t & $\mathrm{p}$-valor \\
\hline constante & $1,31 \mathrm{E}+06$ & $1,03 \mathrm{E}+06$ & 1,275 & 0,2078 \\
\hline D. Vendas & $-0,0391441$ & 0,87004 & $-0,04499$ & 0,9643 \\
\hline D. Adm. & 7,99474 & 3,75703 & 2,128 & $0,0380 * *$ \\
\hline CMV & $-0,437125$ & 0,187474 & $-2,332$ & $0,0236 * *$ \\
\hline \multicolumn{5}{|c|}{ Baixo CF } \\
\hline $\mathrm{R}^{2}$ Within & 0,480791 & & & \\
\hline Teste F & 4,97384 & & & \\
\hline P-valor (F) & $5,88 \mathrm{E}-03$ & & & \\
\hline Observações & 149 & & & \\
\hline Akaike & 4155,628 & & & \\
\hline Variável & Coeficiente & Erro padrão & razão-t & $\mathrm{p}$-valor \\
\hline constante & 223326 & 145603 & 1,534 & 0,1346 \\
\hline D. Vendas & $-0,0557480$ & 0,115392 & $-0,4831$ & 0,6322 \\
\hline D. Adm. & $-0,490248$ & 0,441721 & $-1,110$ & 0,2751 \\
\hline CMV & 0,0783278 & 0,0205634 & 3,809 & $0,0006 * * *$ \\
\hline \multicolumn{5}{|c|}{ Alto CF } \\
\hline $\mathrm{R}^{2}$ Within & 0,439343 & & & \\
\hline Teste F & $6,41 E+04$ & & & \\
\hline P-valor (F) & $3,20 \mathrm{E}-38$ & & & \\
\hline $\mathrm{N}^{\circ}$ observações & 188 & & & \\
\hline Akaike & 3251,06 & & & \\
\hline Variável & Coeficiente & Erro padrão & razão-t & $\mathrm{p}$-valor \\
\hline constante & $1,29 E+06$ & $2,06 \mathrm{E}+06$ & 0,6258 & 0,5389 \\
\hline D. Vendas & 1,26409 & 3,14717 & 0,4017 & 0,6924 \\
\hline D. Adm. & 11,1282 & 3,94215 & 2,823 & $0,0109 * *$ \\
\hline CMV & $-0,623412$ & 0,279057 & $-2,234$ & $0,0377 * *$ \\
\hline \multicolumn{5}{|c|}{ Modelo 4- Previsão analista $t+1=a+b 1$ Materiais e Serviços $t+b 2$ Depreciação $t+b 3$ Pessoal $t+b 4$ Outras $t+\varepsilon t$} \\
\hline \multicolumn{5}{|c|}{ Amostra total } \\
\hline $\mathrm{R}^{2}$ Within & 0,327408 & & & \\
\hline Teste F & 21,1653 & & & \\
\hline P-valor (F) & $1,79 \mathrm{E}-10$ & & & \\
\hline Observações & 246 & & & \\
\hline Akaike & 8061,577 & & & \\
\hline Variável & Coeficiente & Erro padrão & razão-t & $\mathrm{p}$-valor \\
\hline constante & $3,04 \mathrm{E}+06$ & 543500 & 5,59 & $8,05 e-07^{* * *}$ \\
\hline Depreciação & $-2,58362$ & 1,97275 & $-1,310$ & 0,196 \\
\hline Materiais & 0,233386 & 0,210812 & 1,107 & 0,2733 \\
\hline Pessoal & $-0,824003$ & 0,696291 & $-1,183$ & 0,2419 \\
\hline Outras & 0,122337 & 0,0705223 & 1,735 & $0,0886 *$ \\
\hline \multicolumn{5}{|c|}{ Baixo CF } \\
\hline$R^{2}$ Within & 0,562509 & & & \\
\hline Teste F & 30,8489 & & & \\
\hline P-valor (F) & $9,94 \mathrm{E}-11$ & & & \\
\hline
\end{tabular}




\begin{tabular}{|c|c|c|c|c|}
\hline Observações & 149 & & & \\
\hline Akaike & 4132,112 & & & \\
\hline Variável & Coeficiente & Erro padrão & razão-t & p-valor \\
\hline constante & 113051 & 90743,6 & 1,246 & 0,2216 \\
\hline Depreciação & $-0,414091$ & 0,0974692 & $-4,248$ & $0,0002 * * *$ \\
\hline Materiais & 0,0440253 & 0,0115868 & 3,8 & $0,0006 * * *$ \\
\hline Pessoal & 0,342034 & 0,149015 & 2,295 & $0,0282 * *$ \\
\hline Outras & 0,00497481 & 0,0218979 & 0,2272 & 0,8217 \\
\hline \multicolumn{5}{|c|}{ Alto CF } \\
\hline $\mathrm{R}^{2}$ Within & 0,38739 & & & \\
\hline Teste F & 1104,82 & & & \\
\hline P-valor (F) & $3,30 \mathrm{E}-22$ & & & \\
\hline № observações & 97 & & & \\
\hline Akaike & 3261,656 & & & \\
\hline Variável & Coeficiente & Erro padrão & razão-t & $\mathrm{p}$-valor \\
\hline constante & $6,46 E+06$ & $6,83 E+05$ & 9,463 & $1,27 e-08^{* * *}$ \\
\hline Depreciação & $-5,84755$ & 9,32992 & $-0,6268$ & 0,5383 \\
\hline Materiais & 0,725528 & 0,983418 & 0,7378 & 0,4697 \\
\hline Pessoal & $-0,886956$ & 2,37322 & $-0,3737$ & 0,7127 \\
\hline Outras & 0,335642 & 0,309061 & 1,086 & 0,2911 \\
\hline
\end{tabular}

Ainda nesse contexto, se os analistas projetam os seus resultados com base nas despesas por função, espera-se que eles devam apresentar maiores erros de previsão quando analisam empresas com maiores níveis de custos fixos embutidos. Então, com base nessa expectativa, testou-se a validade da hipótese $\mathrm{H} 2$ (Tabela 5).

O $\mathrm{R}^{2}$ do modelo 5 foi de $54 \%$, enquanto o $\mathrm{R}^{2}$ do modelo 6 foi de $86 \%$, mostrando uma maior relação causal entre a apresentação das despesas por natureza e o erro de previsão do analista. Esse resultado mostra que o erro do analista pode ser mais bem explicado pelas variações que ocorrem no método de apresentação das despesas por natureza, já que os resultados anteriores sugerem que o analista não utiliza essa informação em suas projeções.

No entanto, quando se analisa o comportamento dos grupos separadamente, observa-se um resultado ainda mais interessante: nota-se que o grupo "baixo CF" apresenta um poder explicativo muito baixo para os modelos 5 e 6 . Isso sugere que, para empresas que apresentam um menor nível de custos fixos, o erro do analista não pode ser atribuído à forma de apresentação das despesas na DRE.

Por outro lado, quando se analisa o grupo "alto CF", o modelo de despesas por função apresenta um $\mathrm{R}^{2}$ de $65 \%$ e o modelo de despesas por natureza de $92 \%$. Esse resultado sugere que o erro do analista está associado às variações que ocorrem no método de apresentação das despesas por natureza para empresas com maior nível de custos fixos, como esperado, sustentando o argumento de que os analistas utilizam a informação por função e, portanto, erram mais ao analisarem empresas com altos níveis de custos fixos.

Resumidamente, é possível inferir que o erro do analista não pode ser explicado estatisticamente pelo método de apresentação das despesas para empresas com baixo nível de custos fixos. No entanto, quando se trata de empresas com alto nível de custos fixos, grande parte do erro do analista é explicada justamente pelo método de apresentação das despesas, no caso, pelo método de divulgação por natureza. Esses resultados validam a hipótese $\mathrm{H} 2$. 
Tabela 5-Resultados obtidos para a variável dependente erro do analista (H2).

\begin{tabular}{|c|c|c|c|c|}
\hline \multicolumn{5}{|c|}{ Modelo 5- Erro analista $t+1=a+b 1 C M V t+b 2 D$. Vendas $t+b 3$. Administrativas $t+\varepsilon t$} \\
\hline \multicolumn{5}{|c|}{ Amostra total } \\
\hline $\mathrm{R}^{2}$ Within & 0,542794 & & & \\
\hline Teste $\mathrm{F}$ & 26,6522 & & & \\
\hline P-valor (F) & $1,20 \mathrm{E}-10$ & & & \\
\hline Observaçōes & 246 & & & \\
\hline Akaike & 7967,546 & & & \\
\hline Variável & Coeficiente & Erro padrão & razão-t & p-valor \\
\hline constante & $-2,14852 \mathrm{e}+06$ & 813364 & $-2,642$ & $0,0108 * *$ \\
\hline D. Vendas & 0,201009 & 0,687194 & 0,2925 & 0,771 \\
\hline D. Adm. & $-1,80829$ & 0,617587 & $-2,928$ & $0,0050 * * *$ \\
\hline CMV & 0,362938 & 0,0422401 & 8,592 & $1,28 \mathrm{e}-011^{* * *}$ \\
\hline \multicolumn{5}{|c|}{ Baixo CF } \\
\hline $\mathrm{R}^{2}$ & 0,0730456 & & & \\
\hline Teste $\mathrm{F}$ & 7,21016 & & & \\
\hline P-valor (F) & 0,0655 & & & \\
\hline Observaçōes & 149 & & & \\
\hline Akaike & 4171,039 & & & \\
\hline Variável & Coeficiente & Erro padrão & razão-t & $\mathrm{p}$-valor \\
\hline constante & 63495,2 & 37150,8 & 1,7091 & $0,0874 *$ \\
\hline D. Vendas & 0,0150271 & 0,02663 & 0,5643 & 0,5726 \\
\hline D. Adm. & 0,0878118 & 0,132766 & 0,6614 & 0,5084 \\
\hline CMV & 0,0004173 & 0,00316463 & 0,1319 & 0,8951 \\
\hline \multicolumn{5}{|c|}{ Alto CF } \\
\hline $\mathrm{R}^{2}$ Within & 0,656626 & & & \\
\hline Teste F & $5,24 \mathrm{E}+04$ & & & \\
\hline P-valor (F) & $2,19 \mathrm{E}-37$ & & & \\
\hline № observaçöes & 97 & & & \\
\hline Akaike & 3204,915 & & & \\
\hline Variável & Coeficiente & Erro padrão & razão-t & p-valor \\
\hline constante & $-3,35023 e+06$ & $4,77 \mathrm{E}+05$ & $-7,027$ & $1,09 \mathrm{e}-06 * * *$ \\
\hline D. Vendas & 1,7061 & 0,934748 & 1,825 & $0,0837 *$ \\
\hline D. Adm. & $-1,25267$ & 1,77211 & $-0,7069$ & 0,4882 \\
\hline CMV & 0,334606 & 0,119563 & 2,799 & $0,0115 * *$ \\
\hline \multicolumn{5}{|c|}{ Modelo 6- Erro analista $t+1=a+b 1$ Materiais e Serviços $t+b 2$ Depreciação $t+b 3$ Pessoal $t+b 4$ Outras $t \varepsilon t$} \\
\hline \multicolumn{5}{|c|}{ Amostra total } \\
\hline $\mathrm{R}^{2}$ Within & 0,8648 & & & \\
\hline Teste $\mathrm{F}$ & 3243,25 & & & \\
\hline P-valor (F) & $1,23 \mathrm{E}-62$ & & & \\
\hline Observaçōes & 246 & & & \\
\hline Akaike & 7669,824 & & & \\
\hline Variável & Coeficiente & Erro padrão & razão-t & p-valor \\
\hline constante & -304263 & 274208 & $-1,110$ & 0,2722 \\
\hline Depreciação & 2,75386 & 0,816853 & 3,371 & $0,0014 * * *$ \\
\hline Materiais & $-0,131194$ & 0,0831051 & $-1,579$ & 0,1204 \\
\hline Pessoal & 0,433949 & 0,48346 & 0,8976 & 0,3735 \\
\hline Outras & $-0,540152$ & 0,0860203 & $-6,279$ & $6,49 \mathrm{e}-08 * * *$ \\
\hline \multicolumn{5}{|c|}{ Baixo CF } \\
\hline $\mathrm{R}^{2}$ & 0,105704 & & & \\
\hline
\end{tabular}




\begin{tabular}{|c|c|c|c|c|}
\hline Teste F & 10,6926 & & & \\
\hline P-valor (F) & 0,0302 & & & \\
\hline Observações & 149 & & & \\
\hline Akaike & 4167,732 & & & \\
\hline Variável & Coeficiente & Erro padrão & razão-t & $\mathrm{p}$-valor \\
\hline constante & 65348,5 & 34986,7 & 1,8678 & 0,0618 * \\
\hline Depreciação & 0,0365755 & 0,0339356 & 1,0778 & 0,2811 \\
\hline Materiais & 0,0028939 & 0,00336214 & 0,8607 & 0,3894 \\
\hline Pessoal & 0,064628 & 0,0313485 & 2,0616 & $0,0392 * *$ \\
\hline Outras & 0,0043225 & 0,0161492 & 0,2677 & 0,789 \\
\hline \multicolumn{5}{|c|}{ Alto CF } \\
\hline $\mathrm{R}^{2}$ Within & 0,921161 & & & \\
\hline Teste F & 61478,4 & & & \\
\hline P-valor (F) & $9,05 E-39$ & & & \\
\hline № observações & 97 & & & \\
\hline Akaike & 3064,188 & & & \\
\hline Variável & Coeficiente & Erro padrão & razão-t & $\mathrm{p}$-valor \\
\hline constante & -158043 & $4,42 E+05$ & $-0,3573$ & 0,7248 \\
\hline Depreciação & 6,70768 & 0,580346 & 11,56 & $4,87 e-010$ **** \\
\hline Materiais & $-0,513466$ & 0,164044 & $-3,130$ & $0,0055 * * *$ \\
\hline Pessoal & $-1,03069$ & 0,479499 & $-2,150$ & $0,0447 * *$ \\
\hline Outras & $-0,670676$ & 0,139082 & $-4,822$ & $0,0001 * * *$ \\
\hline
\end{tabular}

4.2 Testes de robustez

Com o intuito de trazer maior robustez aos resultados obtidos e tentar corroborar os indícios da maior capacidade preditiva das despesas por natureza, foram realizados alguns testes adicionais. O primeiro é o teste de Chow, que analisa a presença de quebra estrutural entre grupos, e teve como objetivo verificar se realmente existe diferença entre os grupos de empresas quanto ao nível de custos fixos existente. Essa análise é importante, pois a explicação dos resultados está embasada na existência de dois grupos de empresas com diferentes proporções de custos fixos, o que pode afetar a acurácia das projeções dos analistas de mercado.

Os resultados do teste de Chow estão apresentados na Tabela 6 e mostram que existe, de fato, uma quebra estrutural entre os grupos, ou seja, é possível afirmar que os grupos se diferenciam em relação à proporção de custos fixos. Nota-se, ainda, que todas as variáveis são significativas para o modelo 6 (natureza), inclusive a dummy, reiterando-se a análise de que a não utilização da informação por natureza está diretamente relacionada ao erro de projeção dos analistas para empresas com altos níveis de custos fixos. Logo, o teste sustenta que os analistas, provavelmente, não utilizam a informação por natureza em suas previsões e, por isso, acabam errando mais em projeções para empresas com altos custos fixos. 
Tabela 6- Resultados do teste de Chow para a variável erro do analista.

\begin{tabular}{|c|c|c|c|}
\hline \multicolumn{4}{|c|}{ TESTE DE CHOW- Amostra total } \\
\hline \multicolumn{4}{|c|}{ MODELO 5} \\
\hline $\mathrm{R}^{2}$ ajustado & 0,639823 & & \\
\hline Teste F & 5,625404 & & \\
\hline P-valor (F) & $5,08 \mathrm{E}-06$ & & \\
\hline Observações & 246 & & \\
\hline Akaike & 8040,613 & & \\
\hline Teste de Chow (F) & 4,91436 & & \\
\hline Teste de Chow P-valor (F) & 0,0008 & & \\
\hline Variável & Coeficiente & Erro padrão & $\mathrm{p}$-valor \\
\hline constante & 60662,1 & 18945,4 & $0,0016 * * *$ \\
\hline D. Vendas & 0,0115241 & 0,0273278 & 0,6736 \\
\hline D. Adm. & 0,106402 & 0,146133 & 0,4673 \\
\hline CMV & 0,000414918 & 0,00257949 & 0,8723 \\
\hline Dummy & 390378 & 556002 & 0,4833 \\
\hline D. Vendas & $-3,83998$ & 2,04804 & $0,0620 *$ \\
\hline D. Adm. & $-3,12165$ & 3,20193 & 0,3306 \\
\hline CMV & 0,46053 & 0,195498 & $0,0193 * *$ \\
\hline \multicolumn{4}{|c|}{ MODELO 6} \\
\hline $\mathrm{R}^{2}$ ajustado & 0,934364 & & \\
\hline Teste F & 62,00361 & & \\
\hline P-valor (F) & $3,21 E-57$ & & \\
\hline Observações & 246 & & \\
\hline Akaike & 7623,731 & & \\
\hline Teste de Chow (F) & 90,5662 & & \\
\hline Teste de Chow P-valor (F) & 0,00000 & & \\
\hline Variável & Coeficiente & Erro padrão & p-valor \\
\hline constante & $6,28 \mathrm{E}+04$ & 26609,4 & $0,0191 * *$ \\
\hline Amortização & 0,0395825 & 0,0220724 & $0,0742 *$ \\
\hline Materiais & $-0,00304089$ & 0,0013446 & $0,0246 * *$ \\
\hline Pessoal & 0,0679933 & 0,0204644 & $0,0010 * * *$ \\
\hline Outras & $-0,00456162$ & 0,010529 & 0,6652 \\
\hline Dummy & $1,12 \mathrm{E}+06$ & 217152 & $5,05 e-07 * * *$ \\
\hline Depreciação & 6,75923 & 0,807249 & $5,00 \mathrm{e}-015^{* * *}$ \\
\hline Materiais & $-0,443249$ & 0,124742 & $0,0005 \quad * * *$ \\
\hline Pessoal & $-2,18783$ & 0,702886 & $0,0021 \quad * * *$ \\
\hline Outras & $-0,659002$ & 0,0863801 & $5,79 \mathrm{e}-013 * * *$ \\
\hline
\end{tabular}

Um segundo teste de robustez, mais criterioso, foi feito por meio da exclusão de algumas empresas da amostra que apresentavam uma certa peculiaridade na composição da conta "outras despesas". Excluíram-se as empresas que não apresentavam a abertura do CMV por natureza em nota explicativa e que, portanto, tinham um alto valor de despesas alocado à conta de "outras despesas". Feito esse recorte na amostra, os testes foram todos realizados novamente. Foram excluídas 8 empresas, restando 46 empresas na amostra final.

Os resultados, apresentados na Tabela 7, mostram que, mesmo retirando-se as empresas com valores muito elevados em "outras despesas", os resultados se mantiveram muito próximos aos obtidos para a amostra inicial e a análise dos resultados não foi prejudicada. Nota-se que a apresentação das despesas por natureza continua sendo mais preditiva do que a informação por função e o erro do analista é maior 
para empresas com maiores custos fixos, corroborando a hipótese de que o analista utiliza a informação por função para realizar projeções.

Tabela 7- Testes robustos realizados apenas para o grupo de empresas que não apresentavam o valor do CMV alocado à conta "outras despesas".

\begin{tabular}{|c|c|c|c|c|c|c|c|}
\hline \multicolumn{8}{|c|}{ TESTE ROBUSTOS } \\
\hline \multicolumn{8}{|c|}{ MODELO 1- LUCRO LÍQUIDO } \\
\hline \multicolumn{4}{|c|}{ DESPESAS POR FUNÇÃO } & \multicolumn{4}{|c|}{ DESPESAS POR NATUREZA } \\
\hline & Amostra Total & Baixo CF & Alto CF & & Amostra Total & Baixo CF & Alto CF \\
\hline № observações & 208 & 126 & 82 & № observações & 208 & 126 & 82 \\
\hline$R^{2}$ & $50,21 \%$ & $29,45 \%$ & $60,72 \%$ & $\mathrm{R}^{2}$ & $67,89 \%$ & $35,03 \%$ & $75,45 \%$ \\
\hline \multicolumn{8}{|c|}{ MODELO 2-PREVISÃO DO ANALISTA } \\
\hline \multicolumn{4}{|c|}{ DESPESAS POR FUNÇÃO } & \multicolumn{4}{|c|}{ DESPESAS POR NATUREZA } \\
\hline & Amostra Total & Baixo CF & Alto CF & & Amostra Total & Baixo CF & Alto CF \\
\hline № observações & 208 & 126 & 82 & № observações & 208 & 126 & 82 \\
\hline$R^{2}$ & $33,24 \%$ & $48,58 \%$ & $44,58 \%$ & $R^{2}$ & $32,95 \%$ & $57,36 \%$ & $39,35 \%$ \\
\hline \multicolumn{8}{|c|}{ MODELO 3- ERRO DO ANALISTA } \\
\hline \multicolumn{4}{|c|}{ DESPESAS POR FUNÇÃO } & \multicolumn{4}{|c|}{ DESPESAS POR NATUREZA } \\
\hline & Amostra Total & Baixo CF & Alto CF & & Amostra Total & Baixo CF & Alto CF \\
\hline № observações & 208 & 126 & 82 & № observações & 208 & 126 & 82 \\
\hline$R^{2}$ & $54,40 \%$ & $6,69 \%$ & $65,75 \%$ & $R^{2}$ & $87,26 \%$ & $10,35 \%$ & $92,85 \%$ \\
\hline
\end{tabular}

Por fim, o terceiro e último teste de robustez teve o objetivo de corroborar os resultados anteriores, já que lucro e fluxo de caixa são informações bastante correlacionadas, distinguindo-se uma da outra apenas por uma questão de temporalidade. Assim, tendo como base os modelos 1 e 2 utilizados anteriormente, substituiu-se a variável 'lucro líquido' pelo 'fluxo de caixa operacional'- já que esta não está, temporalmente, tão correlacionado com as despesas do período.

Além disso, foi possível analisar a significância das variáveis independentes e dos seus coeficientes, já que não houve problema de multicolinearidade entre as variáveis. Ainda, embora tenha exigido a exclusão de algumas observações, a utilização da técnica de painel dinâmico possibilitou um controle mais rigoroso de endogeneidade no modelo. A seguir está representado o modelo teórico utilizado.

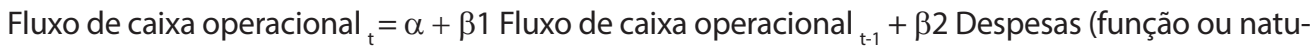

$$
\text { reza) }{ }_{\mathrm{t}-1}+\varepsilon_{\mathrm{t}}(2)
$$

O primeiro teste de painel dinâmico consiste na análise das despesas por função como variáveis independentes e se encontra descrito na Tabela 8. Nota-se que, dentre as variáveis independentes relacionadas à abertura das despesas pelo método da função, apenas as despesas administrativas se mostraram significativas a $1 \%(p<0,001)$ para explicar o fluxo de caixa do período seguinte. Isso sugere que todo o poder explicativo da DRE por função está agregado na variável despesas administrativas. Logo, as despesas com vendas e o custo da mercadoria vendida não apresentaram relevância estatística a um nível de 5\% para explicar as projeções de fluxo de caixa futuro, não mostrando um impacto relevante para a previsão.

Por outro lado, a variável dependente (FCO t-1) defasada mostrou-se significante, como já era esperado que ocorresse com base na literatura sobre fluxo de caixa, o que mostra que grande parte do fluxo de caixa operacional de um período pode ser explicado pelo fluxo de caixa operacional apresentado no 
período anterior (estocasticidade). Além disso, foram analisadas 127 observações e 10 instrumentos foram utilizados no modelo. O teste de Wald rejeitou a hipótese nula, sugerindo que os parâmetros da regressão são estatisticamente significativos. Já o teste de Sargan não rejeitou a hipótese nula, o que sugere que os instrumentos foram validados para o modelo.

Tabela 8- Resultados obtidos para o modelo de apresentação das despesas por função.

\begin{tabular}{|c|c|c|c|c|}
\hline \multicolumn{5}{|c|}{ Painel Dinâmico } \\
\hline \multicolumn{5}{|c|}{ Despesas por função } \\
\hline № Instrumentos & 10 & & & \\
\hline Teste de Sargan & 0,191 & & & \\
\hline Teste de Wald & 0,000 & & & \\
\hline Observações & 127 & & & \\
\hline Variável & Coeficiente & Erro padrão & z & $\mathrm{p}$-valor \\
\hline FCO t-1 & 0,467712 & 0,108929 & 4,294 & $1,76 \mathrm{E}-05^{* * *}$ \\
\hline constante & $-0,00616581$ & 0,00860399 & $-0,7166$ & 0,4736 \\
\hline D. Vendas & 2,0973 & 1,17079 & 1,791 & $0,0732 *$ \\
\hline D. Administrativas & $-1,70025$ & 0,137877 & $-12,33$ & $6,12 \mathrm{E}-35 * * *$ \\
\hline CMV & $-0,156325$ & 0,346791 & $-0,4508$ & 0,6522 \\
\hline
\end{tabular}

De forma semelhante, a Tabela 9 apresenta os resultados obtidos para o modelo que contém as variáveis independentes relacionadas às despesas pelo método da natureza. Diferentemente do modelo anterior, percebe-se que quase todas as variáveis independentes foram significativas com 95\% e 99\% de confiança, com exceção da conta de depreciação, que não apresentou significância. Assim, de acordo com os resultados obtidos, nota-se que a "depreciação" é a única informação sobre despesas que não se mostrou relevante na predição de FCO futuro. Dessa forma, o teste mostra que a maior parte das variáveis apresentadas influencia significativamente no valor de FCO apresentado em ' $t$ ', diferentemente do modelo anterior no qual a variável "despesas administrativas" carrega todo o conteúdo informativo das despesas por função.

Foram analisadas 127 observações e utilizados 11 instrumentos no modelo. Os testes de Sargan e Wald rejeitaram a hipótese nula, indicando a validade dos parâmetros, mas que os instrumentos não foram validados no modelo. Nota-se, ainda, que todas as despesas apresentadas, que foram significativas, apontam para a existência de uma relação de efeito negativo com o fluxo de caixa futuro. Sendo assim, é possível inferir que uma redução nas despesas no período ' $t-1$ ' aumenta o fluxo de caixa divulgado no período ' $t$ ', como esperado inicialmente. Esse raciocínio não se aplica ao fluxo de caixa em 't-1' (defasado) que, assim como no modelo anterior, se relaciona positivamente com o fluxo de caixa do ano seguinte.

Desta forma, comparada à apresentação das despesas pelo método da função, é possível inferir que a apresentação das despesas por natureza é mais informativa quanto ao fluxo de caixa do período seguinte, sendo, portanto, mais útil na projeção de fluxos de caixa futuros. Possivelmente, o maior detalhamento oferecido pela abertura por natureza seja responsável por esse resultado, já que esse método fornece maior conteúdo informativo sobre a origem das despesas e, segundo a norma, exige menos alocações arbitrárias no processo de elaboração das demonstrações contábeis (CPC 26, 2011). 
Tabela 9-Resultados obtidos para o modelo de apresentação das despesas por natureza.

\begin{tabular}{|c|c|c|c|c|}
\hline \multicolumn{5}{|c|}{ Despesas por natureza } \\
\hline \multicolumn{5}{|c|}{ Dinâmico } \\
\hline No Instrumentos & 11 & & & \\
\hline Teste de Sargan & 0,000 & & & \\
\hline Teste de Wald & 0,000 & & & \\
\hline Observações & 127 & Erro padrão & z & p-valor \\
\hline Variável & Coeficiente & 0,136994 & 3,94 & $8,16 \mathrm{E}-05$ *** \\
\hline FCO t-1 & 0,539693 & 0,0102508 & 0,359 & 0,7196 \\
\hline constante & 0,0036802 & 0,951024 & $-1,342$ & 0,1794 \\
\hline Depreciação & $-1,27672$ & 0,325314 & $-2,579$ & $9,90 \mathrm{E}-03$ *** \\
\hline Materiais e Serviços & $-0,838943$ & 0,240272 & $-8,606$ & $7,58 \mathrm{E}-18$ *** \\
\hline Pessoal & $-2,06773$ & 0,345615 & $-2,054$ & $0,0399 * *$ \\
\hline Outras despesas & $-0,709993$ & & & \\
\hline
\end{tabular}

Logo, os testes de robustez realizados sustentam os achados anteriores e mostram que existem evidências empíricas para sustentar as hipóteses propostas. Em resumo, as despesas por natureza carregam maior conteúdo explicativo, individualmente e conjuntamente, do que as despesas classificadas por função.

4.3 Discussão dos resultados

Os resultados apresentados por este estudo contribuem com a literatura ao mostrar que o impedimento de se fazer a escolha contábil do método de apresentação das despesas na DRE pode afetar capacidade dos usuários de predizer fluxos de caixa futuros. Assim, o trabalho traz algumas implicações teóricas e práticas que serão exploradas mais detalhadamente neste tópico.

Em primeiro lugar, do ponto de vista teórico, os resultados sugerem que a apresentação das despesas por natureza é mais preditiva do que a apresentação por função, embora a legislação brasileira oriente a apresentação desta na DRE. Esta evidência corrobora o texto do IAS 1/CPC 26 e torna a nota explicativa sobre despesas por natureza um componente das demonstrações financeiras bastante relevante para os usuários. Ademais, esse resultado também está alinhado com a literatura anterior que apresenta a desagregação e o detalhamento dos componentes do lucro como uma forma melhorar a capacidade preditiva da DRE para os usuários (Dechow \& Ge, 2006; Doukakis, 2010).

Em segundo lugar, ainda sob uma perspectiva teórica, amplia-se, também, os achados de Charitou et al.(2018) e Koonce et al.(2019) no que se refere à relevância das escolhas contábeis que envolvem a apresentação dos itens nas demonstrações financeiras, uma vez que elas também podem interferir na capacidade preditiva da informação que está sendo transmitida ao mercado, assim como ocorre com as escolhas contábeis de reconhecimento e mensuração. Essa informação deve ser de interesse dos normatizadores, já que eles são os responsáveis pela definição dos itens que devem constar na face das demonstrações financeiras e daqueles que devem ser apresentados apenas em nota explicativa, além de definirem quais escolhas contábeis de apresentação devem ser permitidas pelas normas internacionais de contabilidade.

Entretanto, apesar do alto poder preditivo da apresentação das despesas por natureza e da sua disponibilidade em nota explicativa nos demonstrativos das empresas brasileiras, os resultados sugerem que os analistas não utilizam essa informação em suas previsões. Esse resultado corrobora os achados de Frederickson et al. (2006) de que informações reconhecidas nas demonstrações financeiras podem 
ser preferíveis às apresentadas em notas explicativas. Por outro lado, esse resultado também contraria o argumento apresentado por Guo e Zhuo (2018) de que os analistas poderiam ser menos suscetíveis a serem afetados por mudanças no formato de apresentação das despesas na DRE, em decorrência da sua familiaridade e da simplicidade das demonstrações financeiras.

Sendo assim, como contribuição prática, esse estudo fornece indícios de que os analistas utilizam a informação que está disponível na DRE para definirem as suas projeções de resultados, ou seja, embasam as suas análises na segregação das despesas por função, mesmo que a informação por natureza esteja discriminada em nota explicativa.

Não se sabe o motivo para a possível subutilização da informação por natureza pelos analistas, mas esse comportamento pode estar relacionado à uma questão de path dependence do mercado, que faz com que os analistas estejam mais familiarizados com a informação por função e, por isso, sintam-se mais confortáveis em utilizá-la em seus modelos de previsão, mesmo ela sendo uma informação menos preditiva. Outra hipótese seria a de que os analistas desconhecem a qualidade e a capacidade preditiva dessa informação que está disponível e por isso prefiram utilizar a informação que é de mais fácil acesso e que está apresentada na DRE (por função).

Independente da motivação, como consequência desse comportamento, as previsões dos analistas para empresas com maiores níveis de custos fixos tornam-se menos acuradas, já que os resultados dessas companhias são mais difíceis de serem previstos pelo método de apresentação das despesas por função. Isso ocorre porque, em empresas com maiores custos fixos, a apresentação das despesas por natureza facilita a projeção dos resultados, tornando as previsões mais assertivas.

Ainda, os testes de robustez sustentam os resultados obtidos, validando a presença de quebra estrutural entre os grupos de empresas e mostrando que existe heterogeneidade entre os grupos que foram analisados. Os testes robustos permitiram verificar a significância de cada variável independente para o modelo, mostrando que a informação por natureza é, individualmente, mais explicativa de fluxo de caixa futuro quando comparada à informação por função, que concentra a maior parcela do seu poder explicativo na variável "despesas administrativas". Assim, corroborou-se os resultados anteriores, sugerindo que a informação por natureza tem uma relevância global e individual para os modelos de predição propostos.

Ademais, os testes adicionais permitiram ratificar a influência do método de apresentação das despesas na predição de fluxo de caixa futuro de uma forma mais direta, utilizando-se a variável "FCO" como dependente. Logo, foi possível validar os modelos utilizados e mostrar que a questão temporal que diferencia "fluxo de caixa" e "lucro líquido" não afetou os resultados obtidos.

Com isso, espera-se mostrar aos usuários, em especial aos analistas de mercado, a relevância da informação por natureza para a realização de projeções de resultados futuros, assim como mostrar as vantagens de se utilizar essa informação (disponível em nota explicativa para empresas brasileiras), especialmente quando se analisam empresas com alta proporção de custos fixos, buscando-se, assim, reduzir o erro e melhorar a acurácia de suas projeções. 


\section{CONSIDERAÇÕES FINAIS}

Este trabalho contribui com a literatura sobre escolhas contábeis ao mostrar que o impedimento legal no Brasil de se fazer em nível país a escolha contábil de apresentação das despesas na DRE pode afetar a capacidade preditiva do usuário.

Em uma verificação de pressuposto, a apresentação das despesas por natureza mostrou-se mais preditiva de lucro futuro comparada à apresentação das despesas pelo método da função. A partir disso, verificou-se que as despesas por natureza têm menor poder explicativo sobre as previsões dos analistas do que as despesas por função, o que sugere que os analistas utilizam a DRE para suas projeções. Observou-se, também, que as previsões dos analistas são menos acuradas quando as empresas possuem maiores custos fixos, já que estas não são facilmente observáveis na DRE por função.

Assim, a impossibilidade de se fazer a escolha contábil de apresentação das despesas por função ou natureza no Brasil pode afetar a capacidade de os usuários predizerem resultados futuros. Nesse sentido, os resultados empíricos permitem que se questione o artigo 187 da lei 6.404/76, com o intuito de revisar a sua utilidade para o usuário da informação. Dado que o método da natureza se mostrou mais preditivo, a legislação brasileira se põe em sentido oposto aos resultados obtidos ao incentivar a divulgação das despesas por função.

Outra contribuição deste estudo está relacionada à ampliação da literatura sobre as escolhas contábeis que envolvem o formato de apresentação dos itens nos demonstrativos financeiros, já que os resultados apontam evidências de que a apresentação das informações, assim como o seu reconhecimento e mensuração, também pode interferir em sua capacidade preditiva. Ademais, observa-se a maior propensão dos analistas ao uso das informações sobre despesas que estão apresentadas no corpo da DRE (função) em detrimento do detalhamento por natureza divulgado, adicionalmente, em nota explicativa.

Como limitação do estudo, no entanto, destaca-se que, apesar dos indícios de não utilização da informação por natureza pelos analistas, a metodologia utilizada não permite determinar de maneira definitiva que eles de fato não utilizaram essa informação e nem qual teria sido a escolha de apresentação na DRE por parte do gestor. Para tanto, seria necessária a realização de uma investigação adicional com analistas e gestores, o que se sugere para pesquisas futuras.

Sugere-se, ainda, verificar os fatores determinantes que podem levar empresas de outros países a escolherem divulgar as despesas por função, em que há a possibilidade legal de se fazer a escolha contábil da apresentação das despesas na DRE.

REFERÊNCIAS

Anagnostopoulou, S. C. (2010). Does the capitalization of development costs improve analyst forecast accuracy? Evidence from the UK. Journal of International Financial Management \& Accounting, 21(1), 62-83. DOI: https://doi.org/10.1111/j.1467-646X.2009.01036.x

Barth, M. E., Cram, D. P., \& Nelson, K. K. (2001). Accruals and the prediction of future cash flows. The accounting review, 76(1), 27-58. DOI: https://doi.org/10.2308/accr.2001.76.1.27

Basu, S., Hwang, L., \& Jan, C. L. (1998). International variation in accounting measurement rules and analysts' earnings forecast errors. Journal of Business Finance \& Accounting, 25(9-10), 1207-1247. DOI: https://doi.org/10.1111/1468-5957.00234 
Bradshaw, M., Miller, G., \& Serafeim, G. (2009). Accounting choice heterogeneity and analysts' forecasts. University of Michigan Ross School of Business Working Paper.

Brasil, R. F. (2012). Lei n. 6.404, de 15 de dezembro de 1976. Dispõe sobre a Lei das Sociedades por Ações. Disponível em: http://www.planalto.gov.br/ccivil_03/leis/L6404consol.htm. Acesso em 20 nov. 2019.

Bratten, B., Causholli, M., \& Khan, U. (2016). Usefulness of fair values for predicting banks'future earnings: evidence from other comprehensive income and its components. Review of Accounting Studies, 21(1), 280-315. DOI: 10.1007/s11142-015-9346-7

Charitou, A., Karamanou, I., \& Kopita, A. (2018). The determinants and valuation effects of classification choice on the statement of cash flows. Accounting and Business Research, 48(6), 613-650. DOI: https:// doi.org/10.1080/00014788.2017.1407626

Choi, Y. S., Peasnell, K., \& Toniato, J. (2013). Has the IASB been successful in making accounting earnings more useful for prediction and valuation? UK evidence. Journal of Business Finance \& Accounting, 40(78), 741-768. DOI: https://doi.org/10.1111/jbfa.12025

Comitê, D. P. C. (2011). Pronunciamento Técnico CPC 26 (R1): apresentação das demonstrações contábeis. Brasília, DF, 2. DOl: http://www.cpc.org.br/CPC/Documentos-Emitidos/Pronunciamentos/Pronunciamento? Id=57. Acesso em 20 nov. 2019

Cutillas-Gomariz, M. F., Sánchez-Ballesta, J. P., \& Yagüe, J. (2016). The effects of IFRS on net income and earnings components: value relevance, persistence, and predictive value. Spanish Journal of Finance and Accounting/Revista Española de Financiación y Contabilidad, 45(3), 365-388. DOl: https://doi.org/ 10.1080/02102412.2016.1198562

Dalmácio, F. Z., Lopes, A. B., Rezende, A. J., \& Sarlo Neto, A. (2013). Uma análise da relação entre governança corporativa e acurácia das previsões dos analistas do mercado brasileiro. RAM. Revista de Administração Mackenzie, 14(5), 104-139. DOl:https://doi.org/10.1590/\$1678-69712013000500005

Dechow, P. M., \& Ge, W. (2006). The persistence of earnings and cash flows and the role of special items: Implications for the accrual anomaly. Review of Accounting studies, 11(2-3), 253-296. DOI:10.1007/ s11142-006-9004-1

Dechow, P., Ge, W., \& Schrand, C. (2010). Understanding earnings quality: A review of the proxies, their determinants and their consequences. Journal of accounting and economics, 50(2-3), 344-401. DOI: https://doi.org/10.1016/j.jacceco.2010.09.001

Doukakis, L. C. (2010). The persistence of earnings and earnings components after the adoption of IFRS. Managerial Finance, 36(11), 969-980. DOl:https://doi.org/10.1108/03074351011081286

Fairfield, P. M., Sweeney, R. J., \& Yohn, T. L. (1996). Accounting classification and the predictive content of earnings. Accounting Review, 337-355. DOI: https://www.jstor.org/stable/248292

Francis, J., LaFond, R., Olsson, P. M., \& Schipper, K. (2004). Costs of equity and earnings attributes. The accounting review, 79(4), 967-1010. DOI: https://doi.org/10.2308/accr.2004.79.4.967

Frederickson, J. R., Hodge, F. D., \& Pratt, J. H. (2006). The evolution of stock option accounting: Disclosure, voluntary recognition, mandated recognition, and management disavowals. The Accounting Review, 81(5), 1073-1093. DOI: https://doi.org/10.2308/accr.2006.81.5.1073

Gujarati, D. N., \& Porter, D. C. (2011). Econometria básica. 5a edição, Editora Amgh: Porto Alegre.

Guo, Y., \& Zhou, J. (2018). Experimental tests of the salience theory: disaggregated income statements under two economic states. Asia-Pacific Journal of Accounting \& Economics, 25(1-2), 113-127. DOI: https:// doi.org/10.1080/16081625.2016.1266269 
Guragai, B., Attachot, W., \& Peabody, S. D. (2020). Financial statement presentation of discontinued operations: Determinants and consequences. Advances in Accounting, 100472. DOl: https://doi.org/10.1016/j. adiac.2020.100472

Healy, P. M., \& Palepu, K. G. (2001). Information asymmetry, corporate disclosure, and the capital markets: A review of the empirical disclosure literature. Journal of accounting and economics, 31(1-3), 405-440. DOI: https://doi.org/10.1016/S0165-4101(01)00018-0.

Hope, O. K. (2003). Disclosure practices, enforcement of accounting standards, and analysts' forecast accuracy: An international study. Journal of accounting research, 41(2), 235-272. DOI: https://doi.org/10.1111/1475-679X.00102

Jones, D. A., \& Smith, K. J. (2011). Comparing the value relevance, predictive value, and persistence of other comprehensive income and special items. The Accounting Review, 86(6), 2047-2073. DOI: https:// doi.org/10.2308/accr-10133

Koonce, L., Leitter, Z., \& White, B. J. (2019). Linked balance sheet presentation. Journal of Accounting and Economics, 68(1), 101237. DOI: https://doi.org/10.1016/j.jacceco.2019.101237

Lipe, R. C. (1986). The information contained in the components of earnings. Journal of Accounting Research, 37-64. DOI: https://www.jstor.org/stable/2490728

Lim, C. Y., Lim, C. Y., \& Lobo, G. J. (2013). IAS 39 reclassification choice and analyst earnings forecast properties. Journal of accounting and public policy, 32(5), 342-356. DOI: https://doi.org/10.1016/j.jaccpubpol.2013.06.006

Sloan, R. G. (1996). Do stock prices fully reflect information in accruals and cash flows about future earnings? Accounting review, 289-315. DOl: https://www.jstor.org/stable/248290 